\title{
Management of patients with advanced non-small cell lung cancer: role of gefitinib
}

\author{
This article was published in the following Dove Press journal: \\ Biologics: Targets \& Therapy \\ 17 April 2010 \\ Number of times this article has been viewed
}

\begin{abstract}
Vamsidhar Velcheti'
Daniel Morgensztern ${ }^{2,3,4}$

Ramaswamy Govindan ${ }^{3,4}$

'Department of Internal Medicine, Ochsner Clinic Foundation, New Orleans, LA, USA; ${ }^{2}$ Division of Hematology-Oncology, St. Louis Veterans Hospital, St. Louis, MO, USA; ${ }^{3}$ Division of Medical Oncology, Washington University School of Medicine, St. Louis, MO, USA; ${ }^{4}$ Alvin J Siteman Cancer Center, St. Louis, MO, USA
\end{abstract}

\begin{abstract}
Gefitinib is the first epidermal growth factor receptor tyrosine-kinase inhibitor approved for the treatment of advanced non-small cell lung cancer (NSCLC). Its failure to improve survival in a placebo-control study, however, led to its withdrawal in the United States though it is available in many other countries Subsequent studies nevertheless showed comparable efficacy for gefitinib and docetaxel in the second-line therapy. Gefitinib significantly improved progression-free survival compared to chemotherapy in patients with activating mutations in the epidermal growth factor receptor tyrosine kinase mutations. This review will discuss the results of these large randomized studies and discuss the role of gefitinib in the treatment of advanced NSCLC.
\end{abstract}

Keywords: gefitinib, non-small cell lung cancer

\section{Introduction}

Lung cancer is the most common cause of cancer mortality in the United States, with 159,390 deaths estimated for the year 2009 by the American Cancer Society, accounting for $30 \%$ of cancer deaths in men and $26 \%$ of cancer deaths in women. ${ }^{1}$ Approximately $87 \%$ of patients have one of the non-small cell lung cancer (NSCLC) histology subtypes. $^{2}$ The majority of patients present with locally advanced or metastatic disease, ${ }^{3}$ and relapses are common in those undergoing resection with curative intent, even with the use of adjuvant chemotherapy. ${ }^{4}$ Treatment for patients with advanced disease is largely palliative, and the benefits appear to have reached a plateau with conventional platinum-based chemotherapy doublets. ${ }^{5}$ Inhibitors of epidermal growth factor receptor (EGFR) tyrosine kinase (TK) gefitinib and erlotinib are widely used in the treatment of advanced NSCLC. This review will focus on the role of gefitinib in the treatment of patients with advanced NSCLC.

EGFR is a transmembrane glycoprotein, consisting of three main components, including an extracellular ligand-binding domain, a transmembrane region, and a tyrosine kinase (TK) region. Binding of one of the ligands to the extracellular domain, including epidermal growth factor (EGF), transforming growth factor alpha (TGF- $\alpha$ ), beta-cellulin, epiregulin and amphiregulin, leads to receptor dimerization and activation of the TK. The autophosphorylation triggered by the TK promotes multiple intracellular signaling pathways, ultimately causing cancer cell proliferation, invasion, and metastases. ${ }^{6}$ The EGFR pathway may be inhibited by a monoclonal antibody that prevents the ligand binding or by a small molecule that inhibits the TK activity.

Gefitinib is a low-molecular-weight, synthetic anilinoquinazoline compound that inhibits autophosphorylation and downstream signaling by reversibly binding to the
Correspondence: Ramaswamy Govindan Associate Professor, Division of Oncology, Suite 108, 4960 Children's Place,

St. Louis, MO 631 10, USA

Tel + I 3143625737

$\mathrm{Fax}+$ I 3 |4 3627086

Email rgovinda@dom.wustl.edu 
ATP site. Initial pharmacokinetic studies in healthy male volunteers aged 18 to 62 years receiving escalating doses from $1 \mathrm{mg}$ to $75 \mathrm{mg}$ or $100 \mathrm{mg}$ daily for 3 days, or evaluating the effect of food intake after a single dose of $50 \mathrm{mg}$, showed a peak plasma drug concentration $\left(\mathrm{C}_{\max }\right)$ between 3 and 7 hours after administration, with a terminal elimination half-life of 28 hours. $^{7}$ The $\mathrm{C}_{\max }$ was decreased by $34 \%$ with food ingestion, and the prolonged half-life suggested the feasibility of once daily administration. Overall, the treatment was well tolerated, with a similar frequency of adverse effects compared to placebo.

\section{Phase I clinical trials with gefitinib}

The early experience with gefitinib in four open-label multicenter phase I trials included patients with a variety of solid tumors known to have high expression of EGFR, such as NSCLC, breast, head and neck, colon, and ovarian tumors, although individual malignancies were not tested for baseline EGFR. ${ }^{8-11}$ Treatment was overall well tolerated, with the most common adverse events including rash, diarrhea, nausea, anorexia, and asthenia. The lowest dose associated with tumor response was $150 \mathrm{mg}$ daily, and the maximum tolerated dose was established at $700 \mathrm{mg}$ daily. Given concerns of sub-therapeutic dose administration in some patients due to pharmacokinetic variability, the lowest dose chosen for phase II clinical trials was $250 \mathrm{mg}$ daily. The alternative dose of $500 \mathrm{mg}$ daily was selected as the highest tolerated dose by most patients. Among the 100 patients with NSCLC enrolled in the combined 4 studies, 24 achieved stable disease and 10 had partial response.

\section{Single-agent gefitinib in pretreated patients}

The efficacy of gefitinib in NSCLC was evaluated in two multicenter phase II trials, the Iressa Dose Evaluation in Advanced Lung Cancer (IDEAL) studies I and II. Both studies were nonplacebo controlled and evaluated gefitinib at doses of $250 \mathrm{mg}$ or $500 \mathrm{mg}$ daily. The IDEAL-I trial, conducted in 43 centers worldwide, had approximately $50 \%$ of patients from Japan and enrolled patients who had one or two previous chemotherapy regimens, including a platinum-based combination. ${ }^{12}$ There were no significant differences for the dose of $250 \mathrm{mg}$ compared to $500 \mathrm{mg}$, with similar response rates $(18.4 \%$ versus $19 \%)$, disease control rate $(54.4 \%$ versus $51.4 \%)$, progression-free survival (PFS) (2.7 months versus 2.8 months), median overall survival (7.6 months versus 8 months), and 1-year survival (35\% versus 29\%). Response rates were significantly better for Japanese patients compared to non-Japanese (27.5\% versus
$10.4 \% ; P=0.002)$. The IDEAL-II trial was conducted in 30 US centers and enrolled patients with advanced NSCLC and progressive disease after two or more regimens, including a platinum agent and docetaxel. ${ }^{13}$ Similar to IDEAL-I, there were no differences between the $250 \mathrm{mg}$ and $500 \mathrm{mg}$ daily doses according to response rates $(12 \%$ versus $10 \%)$, median survival (7 months versus 6 months), and projected 1-year survival (27\% versus $24 \%$ ). Treatment was well tolerated in both studies, skin rash being the most common side effect. Since the efficacy was similar between the doses and toxicity was more frequent in patients receiving $500 \mathrm{mg}$, the lower dose became the standard. Clinical predictors for response included Japanese patients, women, adenocarcinoma histology, never smokers, and good performance status ( 0 or 1 ). Based on these results, gefitinib received accelerated Food and Drug Administration (FDA) approval on May 5, 2003, as monotherapy for the treatment of locally advanced or metastatic NSCLC after progression following treatment with platinum-based therapy and docetaxel. ${ }^{14}$

Following accelerated approval in the United States, the FDA mandated postmarketing trials for this agent to evaluate its efficacy in prolonging survival in comparison to best supportive care. In the Iressa Survival Evaluation in Lung Cancer (ISEL) trial, ${ }^{15}$ a randomized phase III study enrolling patients aged 18 or older, with advanced NSCLC previously treated with 1 or 2 previous regimens and refractory (progressive disease within 90 days from the last treatment dose) or intolerant to the last treatment, were randomized to gefitinib $250 \mathrm{mg}$ daily or placebo in a ratio of 2 to 1 . A total of 1692 eligible patients were accrued from 28 countries worldwide. The groups were well balanced, 50\% received at least 2 prior chemotherapies, and $90 \%$ of the patients were refractory to the last chemotherapy. After a median followup of 7.2 months, there was no significant benefit for gefitinib compared to placebo according to median survival (5.6 months versus 5.1 months) or estimated 1-year survival (27\% versus $21 \%$ ) (hazard ratio [HR] 0.89, 95\% confidence interval [CI] $0.77-1.02 ; P=0.087)$. Similarly, despite numerically superior median survival (6.3 months versus 5.4 months) and 1-year survival (30\% versus 18\%), the benefit from gefitinib did not reach statistical significance compared to best supportive care in patients with adenocarcinoma (HR 0.84; 95\% CI 0.68-1.03; $P=0.089$ ). Although the primary analysis by log rank test did not show survival benefit for the gefitinib arm, the preplanned supportive Cox's regression analysis, with covariate adjustments identical to the log rank test, showed a statistically significant improvement for gefitinib compared to placebo in both overall population $(P=0.03)$ and adenocarcinoma $(P=0.033)$. 
Additional pre-planned analyses showed better survival for gefitinib compared to placebo in non-smokers (8.9 months versus 6.1 months; $P=0.012)$ and Asians (9.5 months versus 5.5 months, $P=0.01)$. On December 17, 2004, AstraZeneca issued a letter to US physicians reporting the lack of survival improvement for gefitinib, urging them to consider other treatment options. ${ }^{16}$ Gefitinib was essentially replaced by erlotinib after the results of the BR.21 study, ${ }^{17}$ a randomized phase III trial showing improved survival for second-line erlotinib compared to placebo. Although only the erlotinib trial showed a statistically significant survival improvement over placebo, there were similar response rates ( $8 \%$ versus $8.9 \%$ ), stable disease (32\% versus $35 \%$ ), and 1-year survival ( $27 \%$ versus $31 \%$ ) for gefitinib and erlotinib, respectively.

\section{Second-line gefitinib compared to chemotherapy}

Four recent studies compared gefitinib $250 \mathrm{mg}$ daily with docetaxel (60-75 mg/m² every 3 weeks) in patients with advanced NSCLC (Table 1). The Second-line Indication of Gefitinib in NSCLC (SIGN) trial was an international multicenter trial comparing gefitinib to docetaxel in patients with advanced NSCLC progressing through one previous line of chemotherapy. ${ }^{18}$ Between October 2003 and June 2004, 68 patients were randomized to gefitinib and 73 to docetaxel. Response rates, median PFS, and median survival for gefitinib and docetaxel were $13.2 \%$ and $13.7 \%$, 3 months and 3.4 months, and 7.5 months and 7.1 months, respectively. Gefitinib was associated with fewer adverse events overall ( $51.5 \%$ versus $78.9 \%$ ) and grade 3 or 4 toxicity (8.8\% versus $25.4 \%$ ). The Iressa as a Second-line Therapy in Advanced NSCLC (ISTANA) was a multicenter Korean study that enrolled 82 patients to gefitinib and 79 patients to docetaxel. ${ }^{19}$ Response rates for gefitinib were signifi- cantly higher compared to docetaxel (28.1\% versus $7.6 \%$; $P<0.001)$. Gefitinib was also associated with increased PFS $(P=0.044)$, and the overall survival results are still pending. The V-15-32 study was a multicenter Japanese study enrolling patients with advanced NSCLC previously treated with one or two lines of chemotherapy. ${ }^{20}$ Between September 2003 and January 2006, 245 patients were enrolled into the gefitinib arm and 244 to docetaxel. Response rates were significantly superior for the gefitinib arm $(22.5 \%$ versus 12.8\% (OR 2.14; 95\% CI 1.21-3.78, $P=0.009$ ), median PFS was identical in both arms (2 months), and median survival and 1-year survival for gefitinib and docetaxel were 11.5 months and $47.8 \%$ and 14 months and 53.7\%, respectively. Although there were no statistically significant differences in overall survival $(P=0.33)$, the predefined criterion for non-inferiority (upper CI limit for $\mathrm{HR} \leq 1.25$ ) was not achieved (HR 1.12; 95.24\% CI 0.89-1.40). Nevertheless, despite the lack of proven non-inferiority, the similar survival and decreased toxicity for gefitinib showed that this agent remained an effective therapy. The Iressa NSCLC Trial Evaluating Response and Survival versus Taxotere (INTEREST) was a multicenter randomized phase III trial enrolling patients with advanced NSCLC who had been previously treated with a platinum-based chemotherapy. ${ }^{21}$ In this large study, 733 patients received gefitinib and 733 received docetaxel. Compared to docetaxel, gefitinib was associated with similar response rates $(9.1 \%$ versus $7.6 \%$; OR $1.22, P=0.33)$, PFS (2.2 months versus 2.7 months; HR 1.04, $P=0.47$ ), and median overall survival (7.6 months versus 8 months; HR 1.020 ; 95\% CI 0.905-1.150). This study, unlike the V-15-32, met the predefined non-inferiority criterion, which was determined as the upper confidence limit $<1.154$. Subset analyses showed longer survival for never smokers, women, Asian patients, and those with adenocarcinoma, but this survival

Table I Recent studies comparing gefitinib $250 \mathrm{mg}$ daily with docetaxel (60-75 mg/m² every 3 weeks) in patients with advanced NSCLC

\begin{tabular}{|c|c|c|c|c|c|}
\hline Trial (year) & Treatment & Patients & Response (\%) & Median PFS (months) & Median OS (months) \\
\hline \multirow[t]{2}{*}{$\overline{S I G N ~(2005)^{18}}$} & Gefitinib & 68 & 13.2 & 3 & 7.5 \\
\hline & Docetaxel $^{a}$ & 73 & 13.7 & 3.4 & 7.1 \\
\hline \multirow[t]{2}{*}{ ISTANA $(2008)^{19}$} & Gefitinib & 82 & $28.1 \%$ & NR & NR \\
\hline & Docetaxel $^{a}$ & 79 & $7.6 \%$ & NR & NR \\
\hline \multirow[t]{2}{*}{ V-I5-32 (2008) ${ }^{20}$} & Gefitinib & 245 & 22.5 & 2 & 11.5 \\
\hline & Docetaxel $^{\mathrm{b}}$ & 244 & 12.8 & 2 & 14 \\
\hline \multirow[t]{2}{*}{ INTEREST $(2008)^{21}$} & Gefitinib & 733 & 9.1 & 2.2 & 7.6 \\
\hline & Docetaxela & 733 & 7.6 & 2.7 & 8 \\
\hline
\end{tabular}

aDocetaxel $75 \mathrm{mg} / \mathrm{m}^{2}$

bDocetaxel $60 \mathrm{mg} / \mathrm{m}^{2}$

Abbreviations: PFS, progression-free survival; OS, overall survival; NR, not reported. 
prolongation compared to their counterparts was observed in both the gefitinib and docetaxel arms compared to the rest of the population. Similar to the other reported trials, toxicity was significantly lower in the gefitinib arm.

Shepherd and colleagues recently reported the metaanalysis of the four clinical trials comparing gefitinib with docetaxel. ${ }^{22}$ In univariate analysis, gefitinib was associated with increased response rates (OR 1.65; 95\% CI 1.24-2.21, $P=0.0007$ ) but similar PFS (HR 0.96; 95\% CI $0.87-1.05, P=0.37$ ) and overall survival (HR 1.03; 95\% CI $0.93-1.13, P=0.57)$. When adjusted for study, smoking history, number of previous chemotherapy regimens, response to prior therapy, gender, age, and performance status, response rates remained significantly better for gefitinib (OR 1.58; 95\% CI 1.19-2.10, $P=0.001)$, whereas PFS and overall survival were similar. Taken together, the current data suggest that in the second line setting, gefitinib had similar efficacy as docetaxel but was better tolerated even in molecularly unselected patients with advanced NSCLC.

\section{Experience with first-line gefitinib in unselected patients}

Multiple trials have evaluated the use of gefitinib in previously untreated advanced unselected NSCLC patients (Table 2). Reck and colleagues ${ }^{23}$ showed a 5\% response rate with $40 \%$ stable disease in 58 patients. Median PFS and survival were 7 weeks and 29 weeks, respectively. In contrast, Niho and colleagues ${ }^{24}$ showed response rate of $30 \%$ in 40 eligible patients, with median survival of 13.9 months and 1-year survival of $55 \%$. Nevertheless, despite encouraging response rates and survival, 4 patients (10\%) developed interstitial lung disease, which was considered unacceptable, particularly in the firstline setting. The Iressa in NSCLC versus Vinorelbine Investigation in The Elderly (INVITE) was a multicenter randomized phase II trial comparing gefitinib to vinorelbine $30 \mathrm{mg} / \mathrm{m}^{2}$ on days 1 and 8 every 21 days in patients aged 70 or older with chemotherapy-naïve advanced NSCLC. ${ }^{25}$ The median PFS, the primary objective of the study, was 2.7 months in patients treated with gefitinib and 2.9 months in those treated with vinorelbine (HR 1.19, 95\% CI 0.85-1.65, $P=0.31$ ). Median overall survival for gefitinib and vinorelbine were 5.9 months and 8 months, respectively (HR 0.98; 95\% CI 0.66-1.47). Treatment was better tolerated in the gefitinib arm. Two large phase III trials evaluated the role of gefitinib in combination to chemotherapy compared to chemotherapy alone in previously untreated patients with advanced NSCLC. In both the Iressa NSCLC Trial Accessing the Combination Treatment (INTACT)-1 trial, ${ }^{26}$ in which the control arm included cisplatin and gemcitabine, and the INTACT- 2 trial, ${ }^{27}$ with carboplatin and paclitaxel, the addition of gefitinib failed to improve response rates, PFS, median survival time, or 1-year survival. In a subset analysis of patients in the INTACT-2 study with adenocarcinoma and receiving treatment for 90 or more days, the median survival for patients in the low-dose gefitinib arm (250 mg day) was significantly higher than placebo (17.1 months versus 13.6 months, $P=0.05$ ). These findings suggest that sequential therapy with chemotherapy followed by gefitinib, rather than concurrent, may be the optimal schedule, and there could be a role for maintenance gefitinib.

In the phase III West Japan Thoracic Oncology Group 0203, chemotherapy naive patients with advanced NSCLC were randomized to receive either platinum doublet for up to 6 cycles or 3 cycles of the same chemotherapy followed by gefitinib daily until disease progression. ${ }^{28}$ Although there was an improvement in the PFS for patients treated with maintenance gefintinib (4.6 versus 4.2 months, $P<0.001$ ), overall survival, the primary endpoint did not reach statistical significance (13.6 versus 12.8 months, $P=0.10$ ). In the

Table 2 First-line gefitinib in advanced NSCLC

\begin{tabular}{|c|c|c|c|c|c|c|}
\hline Trial/author (year) & Phase & Treatment & Patients & Response (\%) & Median PFS/TTP (months) & Median OS (months) \\
\hline $\operatorname{Reck}(2006)^{23}$ & II & Gefitinib & 58 & 5 & 1.7 & 6.7 \\
\hline Niho $(2006)^{24}$ & II & Gefitinib & 40 & 30 & NA & 13.9 \\
\hline \multirow[t]{2}{*}{ INVITE $(2008)^{25}$} & III & Gefitinib & 97 & 3.1 & 2.7 & 5.9 \\
\hline & & Vinorelbine & 99 & 5.1 & 2.9 & 8 \\
\hline \multirow[t]{3}{*}{ INTACT-I $(2004)^{26}$} & III & $C_{p G m}$ & 324 & 47.2 & 6 & 10.9 \\
\hline & & CpGmGefitinib 250 & 336 & 51.2 & 5.8 & 9.9 \\
\hline & & CpGmGefitinib 500 & 330 & 50.3 & 5.5 & 9.9 \\
\hline \multirow[t]{3}{*}{ INTACT-2 (2004) $)^{27}$} & III & $\mathrm{CbPc}$ & 345 & 30 & 5 & 9.9 \\
\hline & & CbPcGefitinib 250 & 345 & 30.4 & 5.3 & 9.8 \\
\hline & & CbPcGefitinib 500 & 347 & 28.7 & 4.6 & 8.7 \\
\hline
\end{tabular}

Abbreviations: $\mathrm{Cb}$, carboplatin; Cp, cisplatin; Gm, gemcitabine; Pc, paclitaxel; PFS, progression-free survival; TTP, time to progression; NR, not reported. 
subset of patients with adenocarcinoma however, the gefitinib use was associated with better overall survival (15.4 versus 14.3 months, $P=0.03$ ).

\section{Patient selection for gefitinib}

Since initial trials showed improved responses in never smokers, patients with EGFR mutation, and bronchioloalveolar histology (BAC), subsequent studies were developed for these specific patient populations (Table 3 ).

In the multicenter phase II ONCOBELL study ${ }^{29}$ enrolling patients who were never smokers or had EGFR positive by fluorescence in situ hybridization (FISH) and p-AKT positive irrespective of smoking status, the response rate and 1-year survival in the 42 available patients were $48 \%$ and $64 \%$ respectively.

In the randomized phase III Iressa Pan-Asia Study (IPASS), previously untreated patients with adenocarcinoma and history of smoking either less than 100 cigarettes in their lifetime (non-smokers) or 10 pack-year or less quitting tobacco for at least 15 years (former light smokers) were randomize to receive first-line gefitinib $250 \mathrm{mg}$ daily or carboplatin plus paclitaxel. ${ }^{30}$ Response rates were higher for the gefitinib arm in both the overall population $(43 \%$ versus $33 \%, P<0.001)$ and in patients with $E G F R$ mutation $(71.2 \%$ versus $47.3 \%, P<0.001 \%)$. In contrast, the response rate was significantly lower for gefitinib compared to chemotherapy in patients without the EGFR mutation (1.1\% versus $23.5 \%, P=0.001)$. PFS in patients receiving gefitinib was significantly improved in those with $E G F R$ mutation (HR for progression 0.48 ; 95\% CI, 0.36-0.64; $P<0.001$ ) but significantly worse in those without the mutation (HR
1.85; 95\% CI 2.05-3.98; $P<0.001)$. Significant response rates and survival were also observed in a Korean study, where $55 \%$ of the 72 patients achieved survival and $76 \%$ were alive at 1 year. ${ }^{31}$

The two studies evaluating the role of single agent gefitinib in patients with BAC showed response rates of $13 \%$ to $17 \%$, median survival of 13 to 13.3 months, and 1 -year survival rates of 51 to $55 \%$. $^{32,33}$

In addition to clinical correlates, such as ethnicity, gender, histology, and smoking status, several molecular features that are associated with response to EGFR TKIs have been reported. The first predictor for response discovered was the activating EGFR mutations in a small region of the $E G F R$ gene encoding the tyrosine kinase domain. ${ }^{34,35}$ The most common of these mutations are an in-frame deletion of exon 19 and a missense mutation at codon 858 resulting in arginine-leucine substitution (L858R). Several studies showed significant improvement in response rates among patients with activating EGFR gene mutation treated with gefitinib. Small trials, mostly from Japan and enrolling between 16 and 28 patients with EGFR mutation, showed response rates ranging from $50 \%$ to $90 \%$, and PFS from 7.7 months to 13 months. ${ }^{36-40}$ In the two studies reporting 1-year survival, it ranged between $79 \%$ and $88 \%$. In the larger, predominantly non-Asian, iTARGET study, ${ }^{41}$ the response rate and 1-year survival for patients NSCLC harboring the EGFR mutation and treated with first-line gefitinib were $55 \%$ and $73 \%$ respectively.

$E G F R$ gene amplification has also been associated with response to gefitinib. The EGFR gene is located in the chromosome 7 and may be detected by FISH. Cappuzzo and colleagues $^{42}$ showed that true gene amplification by FISH in

Table 3 Single-agent gefitinib in selected patients

\begin{tabular}{|c|c|c|c|c|c|c|}
\hline $\begin{array}{l}\text { Study/author } \\
\text { (year) }\end{array}$ & Setting & Patients & Response (\%) & $\begin{array}{l}\text { PFS/TTP } \\
\text { (months) }\end{array}$ & $\begin{array}{l}\text { Median survival } \\
\text { (months) }\end{array}$ & I-year survival \\
\hline ONCOBELL $(2007)^{29}$ & Never-smokers ${ }^{\mathrm{a}}$ & 42 & 48 & 6.4 & NR & 64 \\
\hline Lee $(2006)^{31}$ & Never-smokers & 55 & 61 & 6.5 & NR & 79 \\
\hline iTARGET $(2008)^{41}$ & EGFR mutation & 31 & 55 & 9.2 & 17.5 & 73 \\
\hline Asahina $(2006)^{36}$ & EGFR mutation & 16 & 75 & 8.9 & NR & 88 \\
\hline ONCOBELL $(2007)^{29}$ & EGFR mutation & 42 & 48 & 6.4 & NR & 64 \\
\hline Inoue $(2006)^{37}$ & EGFR mutation & 16 & 75 & 9.7 & NR & NR \\
\hline Sutani $(2006)^{38}$ & EGFR mutation & 27 & 78 & 9.4 & 15.4 & NR \\
\hline Sunaga $(2007)^{39}$ & EGFR mutation & 19 & 84 & 13 & NR & NR \\
\hline Tamura $(2008)^{40}$ & EGFR mutation & 28 & 75 & 11.5 & NR & 79 \\
\hline West $(2006)^{32}$ & BAC & 101 & 17 & 4 & 13 & 51 \\
\hline Cadranel $(2007)^{33}$ & BAC & 88 & 13 & 2.9 & 13.3 & 55 \\
\hline
\end{tabular}

aPatients were also enrolled if they had EGFR and p-AKT mutations regardless of smoking status.

Abbreviations: EGFR, epidermal growth factor receptor; PFS, progression-free survival;TTP, time to progression; NR, not reported; BAC, bronchioloalveolar carcinoma. 
patients treated with gefitinib (tight $E G F R$ genes clusters and a ratio of $E G F R$ gene to chromosome $\geq 2$, or $\geq 15$ copies of EGFR per cell in 10 or more of the analyzed cells), or high polysomy ( $\geq 4$ copies in $\geq 40 \%$ of cells) were associated with improved response rates $(36 \%$ versus $3 \%, P<0.001)$, time to progression (9 versus 2.2 months, $\mathrm{P}<0.001$ ) and median survival (18.7 versus 10.3 months, $P=0.03$ ) compared to those without these features. In Oncobell study, ${ }^{29}$ patients with EGFR FISH positive status had response rates of $68 \%$ (vs 9.1\% in EGFR FISH negative) and TTP of 7.6 months (vs 2.7 months in EGFR FISH negative). In the retrospective analysis of the ISEL study, ${ }^{15}$ survival patients treated with gefitinib was improved compared to placebo in patients with EGFR amplification by FISH (8.3 versus 4.5 months, $P=0.067)$ and decreased in those low EGFR gene copy (4.3 versus 6.2 months, $P=0.417) .{ }^{43}$ These results contrast to the In the INTEREST trial, ${ }^{21}$ where there was no benefit from the use of gefitinib, compared to docetaxel in patients with EGFR mutation.

Polymorphisms related to the EGFR pathway have been studied to predict response to EGFR TKIs. The intron $1 \mathrm{CA}$ repeat polymorphism has been most studied. Shorter CA repeats are associated with higher response rates and survival in patients treated with EGFR TKIs. ${ }^{44,45}$

K-ras mutations, which are mutually exclusive with EGFR mutations in lung cancer, are most commonly seen in smokers and associated with resistance to gefitinib. Among multiple studies evaluating the use of gefitinib or erlotinib in patients with K-ras mutations, mutations were found in approximately $17 \%$ of patients by pooled analysis, with most trials showed no response to TKIs. ${ }^{46}$ Although K-ras mutations have been strongly associated with cigarette smoking, a recent study on 482 lung adenocarcinomas showed the presence of K-ras mutations $15 \%$ of never smokers, $22 \%$ of former smokers, and $25 \%$ of current smokers. ${ }^{47}$

\section{Summary}

Despite the withdrawal of gefitinib in the United States after the results from the ISEL study, ${ }^{15}$ gefitinib continues to be evaluated in multiple studies and has been shown to have comparable efficacy to standard chemotherapy in the secondline setting. Gefitinib produces stellar and striking results in patients with lung cancer whose tumor cells harbor activating mutations in EGFR TK domain and has now been approved for use in Europe in this molecularly selected population.

\section{Disclosures}

Dr Ramaswamy Govindan has served as a consultant for AstraZeneca and Genentech.

\section{References}

1. Jemal A, Siegel R, Ward E, Hao Y, Xu J, Thun MJ. Cancer statistics, 2009. CA Cancer J Clin. 2009;59(4):225-249.

2. Govindan R, Page N, Morgensztern D, Read W, Tierney R, Vlahiotis A, et al. Changing epidemiology of small-cell lung cancer in the United States over the last 30 years: analysis of the surveillance, epidemiologic, and end results database. J Clin Oncol. 2006;24:(2)4539-4544.

3. Morgensztern D, Goodgame B, Chitneni P, Baggstrom MQ, Gao F, Govindan R. Trends in stage distribution for patients with non-small cell lung cancer: A National Cancer Database Survey. J Clin Oncol (Meeting Abstracts). 2007;25:7598.

4. Pignon JP, Tribodet H, Scagliotti GV, Douillard JY, Shepherd FA, Stephens RJ, et al; LACE Collaborative Group. Lung adjuvant cisplatin evaluation: a pooled analysis by the LACE Collaborative Group. J Clin Oncol. 2008;26(21):3552-3559.

5. Schiller JH, Harrington D, Belani CP, Langer C, Sandler A, Krook J, et al; Eastern Cooperative Oncology Group. Comparison of four chemotherapy regimens for advanced non-small-cell lung cancer. $N$ Engl J Med. 2002;346(2):92-98.

6. Ciardiello F, Tortora G. EGFR antagonists in cancer treatment. $N$ Engl $J$ Med. 2008;358(11):1160-74. Erratum in: N Engl J Med. 2009; 360(15): 1579

7. Swaisland H, Laight A, Stafford L, Jones H, Morris C, Dane A, et al. Pharmacokinetics and tolerability of the orally active selective epidermal growth factor receptor tyrosine kinase inhibitor ZD1839 in healthy volunteers. Clin Pharmacokinet. 2001;40(4):297-306.

8. Ranson M, Hammond LA, Ferry D, Kris M, Tullo A, Murray PI, et al. ZD1839, a selective oral epidermal growth factor receptor-tyrosine kinase inhibitor, is well tolerated and active in patients with solid, malignant tumors: results of a phase I trial. J Clin Oncol. 2002; 20(9):2240-2250.

9. Herbst RS, Maddox AM, Rothenberg ML, Small EJ, Rubin EH, Baselga J, et al. Selective oral epidermal growth factor receptor tyrosine kinase inhibitor ZD1839 is generally well-tolerated and has activity in non-small-cell lung cancer and other solid tumors: results of a phase I trial. J Clin Oncol. 2002;20(18):3815-3825.

10. Baselga J, Rischin D, Ranson M, Calvert H, Raymond E, Kieback DG, et al. Phase I safety, pharmacokinetic, and pharmacodynamic trial of ZD1839, a selective oral epidermal growth factor receptor tyrosine kinase inhibitor, in patients with five selected solid tumor types. J Clin Oncol. 2002;20(21):4292-4302.

11. Nakagawa K, Tamura T, Negoro S, Kudoh S, Yamamoto N, Yamamoto N, et al. Phase I pharmacokinetic trial of the selective oral epidermal growth factor receptor tyrosine kinase inhibitor gefitinib ('Iressa', ZD1839) in Japanese patients with solid malignant tumors. Ann Oncol. 2003;14(6):922-930.

12. Fukuoka M, Yano S, Giaccone G, Tamura T, Nakagawa K, Douillard JY, et al. Multi-institutional randomized phase II trial of gefitinib for previously treated patients with advanced non-small-cell lung cancer (The IDEAL 1 Trial) [corrected] J Clin Oncol. 2003;21(12):2237-2246. Erratum in: J Clin Oncol. 2004;22(23):4811.

13. Kris MG, Natale RB, Herbst RS, Lynch TJ Jr, Prager D, Belani CP, et al. Efficacy of gefitinib, an inhibitor of the epidermal growth factor receptor tyrosine kinase, in symptomatic patients with nonsmall cell lung cancer: a randomized trial. JAMA. 2003;290(16): 2149-2158.

14. Cohen MH, Williams GA, Sridhara R, Chen G, Pazdur R. FDA drug approval summary: gefitinib (ZD1839) (Iressa) tablets. Oncologist. 2003;8(4):303-306. 
15. Thatcher N, Chang A, Parikh P, Rodrigues Pereira J, Ciuleanu T, von Pawel J, et al. Gefitinib plus best supportive care in previously treated patients with refractory advanced non-small-cell lung cancer: results from a randomised, placebo-controlled, multicentre study (Iressa Survival Evaluation in Lung Cancer). Lancet. 2005;366(9496): $1527-1537$.

16. Comis RL. The current situation: erlotinib (Tarceva) and gefitinib (Iressa) in non-small cell lung cancer. Oncologist. 2005;10(7): 467-470.

17. Shepherd FA, Rodrigues Pereira J, Ciuleanu T, Tan EH, Hirsh V, Thongprasert S, et al; National Cancer Institute of Canada Clinical Trials Group. Erlotinib in previously treated non-small-cell lung cancer. $N$ Engl J Med. 2005;353(2):123-132.

18. Cufer T, Vrdoljak E, Gaafar R, Erensoy I, Pemberton K; SIGN Study Group. Phase II, open-label, randomized study (SIGN) of single-agent gefitinib (IRESSA) or docetaxel as second-line therapy in patients with advanced (stage IIIb or IV) non-small-cell lung cancer. Anticancer Drugs. 2006;17(4):401-409.

19. Lee D, Kim S, Park K, et al. A randomized open-label study of gefitinib versus docetaxel in patients with advanced/metastatic non-small cell lung cancer (NSCLC) who have previously received platinum-based chemotherapy. J Clin Oncol (Meeting Abstracts). 2008;26:8025.

20. Maruyama R, Nishiwaki Y, Tamura T, Yamamoto N, Tsuboi M, Nakagawa K, et al. Phase III study, V-15-32, of gefitinib versus docetaxel in previously treated Japanese patients with non-small-cell lung cancer. J Clin Oncol. 2008;26(26):4244-4252.

21. Kim ES, Hirsh V, Mok T, Socinski MA, Gervais R, Wu YL, et al. Gefitinib versus docetaxel in previously treated non-smallcell lung cancer (INTEREST): a randomised phase III trial. Lancet. 2008;372(9652):1809-1818.

22. Shepherd FA, Douillard J, Fukuoka M, et al. Comparison of gefitinib and docetaxel in patients with pretreated advanced non-small cell lung cancer (NSCLC): Meta-analysis from four clinical trials. J Clin Oncol (Meeting Abstracts). 2009;27:8011.

23. Reck M, Buchholz E, Romer KS, Krutzfeldt K, Gatzemeier U, Manegold C. Gefitinib monotherapy in chemotherapy-naive patients with inoperable stage III/IV non-small-cell lung cancer. Clin Lung Cancer. 2006;7(6):406-411.

24. Niho S, Kubota K, Goto K, Yoh K, Ohmatsu H, Kakinuma R, et al. First-line single agent treatment with gefitinib in patients with advanced non-small-cell lung cancer: a phase II study. J Clin Oncol. 2006;24(1):64-69.

25. Crinò L, Cappuzzo F, Zatloukal P, Reck M, Pesek M, Thompson JC, et al. Gefitinib versus vinorelbine in chemotherapy-naive elderly patients with advanced non-small-cell lung cancer (INVITE): a randomized, phase II study. J Clin Oncol. 2008;26(26):4253-4260.

26. Giaccone G, Herbst RS, Manegold C, Scagliotti G, Rosell R, Miller V, et al. Gefitinib in combination with gemcitabine and cisplatin in advanced non-small-cell lung cancer: a phase III trial-INTACT $1 . J$ Clin Oncol. 2004;22(5):777-784.

27. Herbst RS, Giaccone G, Schiller JH, Natale RB, Miller V, Manegold C, et al. Gefitinib in combination with paclitaxel and carboplatin in advanced non-small-cell lung cancer: a phase III trial-INTACT 2. J Clin Oncol. 2004;22(5):785-794

28. Hida I, Okamoto T, Kashii M, Satouchi Y, Ichinose N, Katakami, et al. Randomized phase III study of platinum-doublet chemotherapy followed by gefitinib versus continued platinum-doublet chemotherapy in patients (pts) with advanced non-small cell lung cancer (NSCLC): Results of West Japan Thoracic Oncology Group trial (WJTOG). J Clin Oncol. 2008;26:LBA8012.

29. Cappuzzo F, Ligorio C, Janne PA, et al. Prospective study of gefitinib in epidermal growth factor receptor fluorescence in situ hybridization positive/phospho-akt-positive or never smoker patients with advanced non-small-cell lung cancer: The ONCOBELL Trial. J Clin Oncol. 2007;25(16):2248-2255.
30. Mok TS, Wu YL, Thongprasert S, Yang CH, Chu DT, Saijo N, et al. Gefitinib or carboplatin-paclitaxel in pulmonary adenocarcinoma. $N$ Engl J Med. 2009;361(10): 947-957.

31. Lee DH, Han JY, Yu SY, Kim HY, Nam BH, Hong EK, et al. The role of gefitinib treatment for Korean never-smokers with advanced or metastatic adenocarcinoma of the lung: a prospective study. $J$ Thorac Oncol. 2006;1(9):965-971.

32. West HL, Franklin WA, McCoy J, Gumerlock PH, Vance R, Lau DH, et al. Gefitinib therapy in advanced bronchioloalveolar carcinoma: Southwest Oncology Group Study S0126. J Clin Oncol. 2006; 24(12):1807-1813.

33. Cadranel J, Quoix E, Debove P, et al. Intergroupe Francophone de Cancerologie Thoracique (IFCT), IFCT0401 trial: Phase II study of gefitinib administered as first-line treatment in non-resectable adenocarcinoma with bronchioloalveolar carcinoma features (ADC-BAC): Final results on efficacy and survival. J Clin Oncol (Meeting Abstracts). 2007;25:7560.

34. Lynch TJ, Bell DW, Sordella R, et al; Activating mutations in the epidermal growth factor receptor underlying responsiveness of non small-cell lung cancer to gefitinib. N Engl J Med. 2004;350(21): 2129-2139.

35. Paez JG, Janne PA, Lee JC, et al: EGFR mutations in lung cancer: Correlation with clinical response to gefitinib therapy. Science. 2004;304(5676):1497-1500.

36. Asahina H, Yamazaki K, Kinoshita I, Sukoh N, Harada M, Yokouchi H, et al. A phase II trial of gefitinib as first-line therapy for advanced nonsmall cell lung cancer with epidermal growth factor receptor mutations. Br J Cancer. 2006;95(8):998-1004.

37. Inoue A, Suzuki T, Fukuhara T, Maemondo M, Kimura Y, Morikawa N, et al. Prospective phase II study of gefitinib for chemotherapy-naive patients with advanced non-small-cell lung cancer with epidermal growth factor receptor gene mutations. J Clin Oncol. 2006;24(21): 3340-3346.

38. Sutani A, Nagai Y, Udagawa K, Uchida Y, Koyama N, Murayama Y, et al. Gefitinib for non-small-cell lung cancer patients with epidermal growth factor receptor gene mutations screened by peptide nucleic acid-locked nucleic acid PCR clamp. Br J Cancer. 2006;95(11): 1483-1489.

39. Sunaga N, Tomizawa Y, Yanagitani N, Iijima H, Kaira K, Shimizu K, et al. Phase II prospective study of the efficacy of gefitinib for the treatment of stage III/IV non-small cell lung cancer with EGFR mutations, irrespective of previous chemotherapy. Lung Cancer. 2007;56(3): 383-389.

40. Tamura K, Okamoto I, Kashii T, Negoro S, Hirashima T, Kudoh S, et al; West Japan Thoracic Oncology Group. Multicentre prospective phase II trial of gefitinib for advanced non-small cell lung cancer with epidermal growth factor receptor mutations: results of the West Japan Thoracic Oncology Group trial (WJTOG0403). Br J Cancer. 2008;98(5):907-914.

41. Sequist LV, Martins RG, Spigel D, Grunberg SM, Spira A, Jänne PA, et al. First-line gefitinib in patients with advanced non-small-cell lung cancer harboring somatic EGFR mutations. J Clin Oncol. 2008;26(15): 2442-2449. Erratum in: J Clin Oncol. 2008;26(20):3472.

42. Cappuzzo F, Hirsch FR, Rossi E, Bartolini S, Ceresoli GL, Bemis L, et al. Epidermal growth factor receptor gene and protein and gefitinib sensitivity in non-small cell lung cancer. J Natl Cancer Inst. 2005;97(9):643-655.

43. Hirsch FR, Varella-garcia M, Bunn PA, Franklin WA, Dziadziuszko R, Thatcher N, et al. Molecular predictors of outcome with gefitinib in a phase III placebo-controlled study in advanced non-small cell lung cancer. J Clin Oncol. 2006;24(321):5034-5042.

44. Nie Q, Wang Z, Zhang GC et al. The epidermal growth factor receptor intron 1 (CA) microsatellite polymorphim is a potential predictor of treatment outcome in patients with advanced lung cancer treated with gefitinib. Eur J Pharmacol. 2007;570(1-3):175-181. 
45. Liu G, Gurubhagavatula S, Zhou W, et al. Epidermal growth factor receptor polymorphisms and clinical outcomes in non-small cell lung cancer patients treated with gefitinib. Pharmacogenomics $J$. 2008;8(2):129-138.

46. Riely GJ, Marks J, Pao W. KRAS Mutations in non-small cell lung cancer. Proc Am Thorac Soc. 2009;6(2):201-205.
47. Riely GJ, Kris MG, Rosenbaum D, et al. Frequency and distinctive spectrum of KRAS mutations in never smokers with lung adenocarcinoma. Clin Cancer Res. 2008;14(18):5731-5734.

\section{Publish your work in this journal}

Biologics: Targets \& Therapy is an international, peer-reviewed journal focusing on the patho-physiological rationale for and clinical application of Biologic agents in the management of autoimmune diseases, cancers or other pathologies where a molecular target can be identified. This journal is indexed on PubMed Central, CAS,
EMBase, Scopus and the Elsevier Bibliographic databases. The manuscript management system is completely online and includes a very quick and fair peer-review system, which is all easy to use. Visit http://www.dovepress.com/testimonials.php to read real quotes from published authors. 